\title{
Rubéola na Gestação: Repercussões Sobre o Produto Conceptual
}

Autor: Denise Araújo Lapa Pedreira

Orientador: Prof. Dr. Marcelo Zugaib

Tese de Doutorado apresentada à Faculdade de Medicina, Universidade de São Paulo - Clínica Obstétrica da Faculdade de Medicina da USP - São Paulo, em 02/12/98.

Objetivos: Avaliar os efeitos da rubéola durante a gestação, sobre o feto, o recém-nascido e a criança.

Casuística e Método: Analisamos 35 gestantes com suspeita de rubéola. Grupo 1: 15 pacientes que apresentaram quadro clínico com comprovação sorológica. Grupo 2: 20 pacientes com IgM positiva na rotina pré-natal, na ausência de quadro clínico. Foi realizada ultra-sonografia mensal, propedêutica invasiva, ecocardiografia fetal e Dopplervelocimetria. Os recém-nascidos vivos foram avaliados pelo exame clínico, sorológico, potencial evocado auditivo, ultra-sonografia de crânio, fundo de olho e ecocardiografia.

Resultados: Grupo 1: a transmissão vertical entre 2 a 14 semanas foi de $64,9 \%$. A malformação ocorreu em $37,5 \%$ dos infectados. A ultra-sonografia revelou crescimento intrauterino retardado simétrico em todos os fetos infectados, em média com 25,1 semanas. Todos os fetos infectados submetidos a cordocentese apresentavam IgM positiva e eritroblastose. A PCR no líquido amniótico foi positiva nos
3 casos em que ela foi realizada. A idade gestacional média do parto entre os infectados foi de 33,8 semanas e o peso médio ao nascimento foi 1365,6 g. Todos os 6 nascidos vivos infectados foram classificados como pequenos para a idade gestacional e apresentaram disacusia. A sobrevida entre os infectados, num seguimento pós-natal médio de 35,2 meses, foi de $62,5 \%$. Grupo 2: a infecção não foi comprovada em nenhum dos recém-nascidos vivos, porém em um caso pudemos demonstrar a infecção congênita pelo virus de Epstein-Barr.

Conclusões: o diagnóstico pré-natal é confiável e o encontro isolado de IgM positiva não se correlacionou com a transmissão vertical, no entanto outras infecções devem ser suspeitadas.

Palavras-chave: Rubéola. Diagnóstico pré-natal. Líquido amniótico. Crescimento intra-uterino retardado.

\section{Estudo de Proteínas do Fluido Peritoneal pela Técnica de Eletroforese em Mulheres Inférteis com Endometriose}

Autor: Fernando Monteiro de Freitas

Orientador: Prof ${ }^{a} \operatorname{Dr}^{a}$ Anaglória Pontes

Tese apresentada ao curso de Pós-Graduação em Ginecologia e Obstetrícia, Área de Concentração em Ginecologia da Faculdade de Medicina de Botucatu - UNESP, para obtenção do Título de Doutor, em 29/4/98.

Estudou-se a concentração de proteínas no "pool" de fluídos peritoneais de grupos de mulheres férteis (5), mulheres inférteis de causa desconhecida (5) e de mulheres inférteis com endometriose (5). O fluido peritoneal foi coletado através de laparoscopia. O grupo de mulheres com endometriose e infertilidade apresentava os estágios I e II da classificação revisada da "American Fertility Society". As proteínas identificadas pela técnica de eletroforese unidimensional com o gel de poliacrilamida $10 \%$ foram as de peso molecular 21-kd, 51-kd, 107-kd e 127-kd. Não houve diferença significativa entre as concentrações de proteínas nos diferentes grupos, sendo que o maior percentual de concentração proteica foi a de $51 \mathrm{kd}$ e a menor de $21 \mathrm{kd}$, ambos no "pool" de pacientes inférteis com endometriose. Necessitam de maior confirmação as evidências encontradas de que a infertilidade dos grupos estudados possa estar correlacionada com as alterações do perfil de proteínas do líquido peritoneal. As concentrações protéicas no "pool" dos fluidos peritoneais dos grupos estudados são sugestivas de que a infertilidade de causa infertilidade com a endometriose sejam o espectro da mesma doença. Outras pesquisas são necessárias para confirmar ou afirmar esta suposição.

Palavras-chave: Endometriose. Implante endometriótico. Fluido peritoneal. Análise protéica. 